\title{
Genetic analysis of the SOD1 and C9ORF72 genes in Hungarian patients with amyotrophic lateral sclerosis
}

\author{
Kornélia Tripolszki ${ }^{a}$, Bernadett Csányi ${ }^{\mathrm{b}}$, Dóra Nagy ${ }^{\mathrm{a}}$, Antonia Ratti ${ }^{\mathrm{c}, \mathrm{d}}$, Cinzia Tiloca ${ }^{\mathrm{c}}$, \\ Vincenzo Silani $^{c, d}$, Éva Kereszty ${ }^{\text {b }}$, Nóra Török ${ }^{\mathrm{e}}$, László Vécsei ${ }^{\mathrm{e}, \mathrm{f}}$, József I. Engelhardt ${ }^{\mathrm{e}}$, \\ Péter Klivényi ${ }^{\mathrm{e}}$, Nikoletta Nagy ${ }^{\mathrm{a}, \mathrm{g}, *, 1}$, Márta Széll ${ }^{\mathrm{a}, \mathrm{g}, 1}$ \\ ${ }^{a}$ Department of Medical Genetics, University of Szeged, Szeged, Hungary \\ ${ }^{\mathrm{b}}$ Department of Forensic Medicine, University of Szeged, Szeged, Hungary \\ ${ }^{c}$ Department of Neurology and Laboratory of Neuroscience, IRCCS Istituto Auxologico Italiano, Milan, Italy \\ d Department of Pathophysiology and Transplantation, "Dino Ferrari" Center, Università degli Studi di Milano, Milan, Italy \\ e Department of Neurology, University of Szeged, Szeged, Hungary \\ ${ }^{\mathrm{f}}$ MTA-SZTE Neuroscience Research Group, University of Szeged, Szeged, Hungary \\ ${ }^{\mathrm{g}}$ MTA SZTE Dermatological Research Group, University of Szeged, Szeged, Hungary
}

\section{A R T I C L E I N F O}

\section{Article history:}

Received 23 November 2016

Received in revised form 16 January 2017

Accepted 20 January 2017

\section{Keywords:}

ALS

SOD1

C9ORF72

Mutation screening

Repeat expansion

\begin{abstract}
A B S T R A C T
Amyotrophic lateral sclerosis (ALS) is a neurodegenerative disease characterized by the death of motor neurons. To date, more than 20 genes have been implicated in ALS, and of these, the 2 most frequently mutated are the superoxide dismutase 1 (SOD1) gene and the chromosome 9 open reading frame 72 (C9ORF72) gene. In this study, we aimed to investigate the contribution of these 2 Mendelian genes to the development of the disease in Hungarian ALS patients $(n=66)$. Direct sequencing of the SOD1 gene revealed a novel (p.Lys91ArgfsTer8) and 3 recurrent heterozygous mutations (p.Val14Met, p.Asp90Ala, and p.Leu144Phe) in 5 patients. The novel p.Lys91ArgfsTer8 mutation led to a frameshift causing the addition of 8 new amino acids, including a premature stop codon at position 99. The GGGGCC hexanucleotide repeat expansion of the C9ORF72 gene was present in 1 ALS patient. This study represents the first genetic analysis of 2 major ALS causative genes in a cohort of Hungarian ALS patients and contributes to the further understanding of the genetic and phenotypic diversity of ALS.
\end{abstract}

(C) 2017 Elsevier Inc. All rights reserved.

\section{Introduction}

Amyotrophic lateral sclerosis (ALS; ORPHA803), also known as "Lou Gehrig's disease", is a fatal, neurodegenerative disorder characterized by the death of motor neurons in the brain, brainstem, and spinal cord, resulting in fatal paralysis (Morrison and Harding, 1994). Familial forms account for about $10 \%$ of ALS cases, whereas other cases are sporadic (Hewitt et al., 2010; Strong et al., 1991). Familial forms are mainly transmitted in a Mendelian pattern of autosomal dominant inheritance (Hardiman et al., 2011). Regarding its genetic background, more than 20 genes have been implicated in the development of ALS (Amyotrophic Lateral Sclerosis Online Genetics Database, [ALSoD], http://alsod.iop.kcl.ac.uk).

\footnotetext{
* Corresponding author at: Department of Medical Genetics, University of Szeged, 6 Somogyi Bela Street, 6720 Szeged, Hungary. Tel.: +36-62-545134; fax: +36-62545699.

E-mail addresses: nikoletta.nagy@gmail.com, nagy.nikoletta@med.u-szeged.hu (N. Nagy).

${ }^{1}$ These two authors contributed equally to this work.
}

Among the ALS causative genes, superoxide dismutase 1 (SOD1) is one of the most commonly mutated genes and accounts for approximately $12 \%-23 \%$ of the familial and up to $7 \%$ of the sporadic ALS forms (Andersen, 2006). SOD1 gene encodes the $\mathrm{Cu} / \mathrm{Zn}$ superoxide dismutase enzyme, which catalyzes the inactivation of superoxide into oxygen and hydrogen peroxide, providing antioxidant defense (Smirnoff, 1993). To date, more than 170 mutations have been reported for SOD1 in the ALSoD Database (Abel et al., 2012) since the gene was firstly associated to ALS in 1993 (Rosen et al., 1993). SOD1 mutations occur in all the 5 exons of the gene.

Another frequently mutated ALS gene is chromosome 9 open reading frame 72 (C9ORF72), which-in addition to the SOD1 mutations-is now recognized as the main cause of familial and sporadic ALS (Gijselinck et al., 2012; Majounie et al., 2012; Ratti et al., 2012; Smith et al., 2013). A hexanucleotide (GGGGCC) repeat expansion ( $R E$ ) located in the noncoding region of the gene that can reach up to 4400 units (normal range: $2-23$ units) has been identified in patients with ALS and/or frontotemporal dementia. The GGGGCC RE contributes to $23 \%-47 \%$ of familial ALS and 
to $4 \%-5 \%$ of sporadic cases (Byrne et al., 2012; DeJesus-Hernandez et al., 2011; Ratti et al., 2012; Renton et al., 2011), with a frequency depending on geographical origin. Although the pathomechanism with which the hexanucleotide RE leads to the development of ALS has not been elucidated completely, both C9orf72 haploinsufficiency gain of function mechanisms (driven by toxicity of sense and antisense RNA transcripts and derived dipeptide repeat proteins) have been reported (Taylor et al., 2016).

In this study, we have investigated the contributions of the 2 most commonly mutated ALS genes, SOD1 and C9ORF72, to the pathogenesis of the disease in Hungarian patients $(n=66)$. This study represents the first genetic screening of ALS in Hungary, which adds novel data to the genetic and phenotypic diversity of this disease.

\section{Patients and methods}

\subsection{Investigated individuals}

The unrelated patients $(n=66)$ included in this study were recruited from the Department of Neurology, University of Szeged, Szeged, Hungary, between 2010 and 2016. All patients fulfilled the El Escorial criteria for ALS (Brooks et al., 2000). Of the 66 cases, only 1 patient reported other affected family members; the other 65 cases were considered sporadic. All patients were of Hungarian ancestry. The study was approved by the Internal Ethical Review Board of the University of Szeged. Written informed consent was obtained from all patients, and the study was conducted according to the Principles of the Declaration of Helsinki.

\subsection{Genetic analyses}

Blood samples were collected from all the enrolled individuals $(\mathrm{n}=66)$, and genomic DNA was isolated using a BioRobot EZ1 DSP Workstation (QIAGEN; Godollo, Hungary). The entire coding region of the SOD1 gene and the flanking introns were amplified (primer sequences used were taken from the UCSC Genome Browser www. genome.ucsc.edu). Direct sequencing of the PCR products was performed on an $\mathrm{ABI} 3100$ sequencer and compared with the wildtype gene sequences at the Ensemble Genome Browser (http:// ensemble.org). To identify known variations, we used ALS Online Genetics Database (http://alsod.iop.kcl.ac.uk/) (Abel et al., 2012), 1000 Genomes Database (www.1000genomes.org/), short genetic variations (http://www.ncbi.nlm.nih.gov/project/SNP), and Exome Aggregation Consortium (ExAC) database (http://exac. broadinstitute.org). To predict the functional effects of novel mutations, the sequence variations were assessed by in silico prediction programs, such as sorting intolerant from tolerant (http://sift. bii.a-star.edu.sg/), Polyphen-2 (http://genetics.bwh.harvard.edu/ pph2), and Mutation Taster (http://mutationtaster.org). To examine possible effects of the mutations on the three-dimensional (3-D) structure of the SOD1 protein, we used the Swiss-Model protein structure homology-modeling server (http://swissmodel. expasy.org/; SOD1 Protein Data Bank accession number 4b3e.1.A).

A 2-step protocol was followed for the detection of the GGGGCC hexanucleotide RE in the C9ORF72 gene. Fragment-length analysis was performed using GeneMapper ID v3.2.1., and the samples producing a single peak product were further analyzed in the second step by repeat-primed PCR using a 310 ABI Prism Genetic Analyzer (Applied Biosystems). The peaks were visualized using GeneMapper ID v3.2.1. software (Akimoto et al., 2014). The presence of the GGGGCC RE was observed as a saw-tooth pattern with 6-base pair periodicity.

To determine whether the single individual carrying the GGGGCC RE identified in this study also carried the "risk" haplotype, we selected the rs3849942 variant to be used as a marker for the "risk" haplotype for the patient and control genotypes. Rs3849942 genotyping was based on allelic discrimination assays using TaqMan chemistry following the manufacturer's instructions (Life Technologies; Budapest, Hungary).

\section{Results}

The direct DNA sequencing approach identified 4 different mutations of the SOD1 gene in 5 ALS patients: 3 known heterozygous missense mutations (c.43 G>A p.Val14Met; c.272 A>C p.Asp90Ala; and c.435 G>C p.Leu144Phe) and 1 novel mutation (c.275_276delAA, p.Lys91ArgfsTer8; Table 1).

The detected novel heterozygous mutation (c.275_276delAA, p.Lys91ArgfsTer8) is located in the fourth exon of the SOD1 gene (Fig. 1A) and led to a frameshift with the insertion of 8 novel amino acids and the formation of premature stop codon at the new amino acid position 99. Analysis using Mutation Taster software predicted that the p.Lys91ArgfsTer8 mutation causes severe truncation of the encoded enzyme, and, thus, we hypothesize that this mutation is likely to be pathogenic (Fig. 1B). The pathogenic role of the p.Lys91ArgfsTer8 mutation is further supported by the fact that it interferes with the integrity of the Cys57-Cys146 disulfide bond and results in the weakening of the dimer interface.

The novel p.Lys91ArgfsTer8 SOD1 mutation was neither present in 110 healthy controls of Hungarian ancestry that we investigated nor it is represented in mutation databases, including Single Nucleotide Polymorphism Database (http://www.ncbi.nlm. nih.gov/projects/SNP/), 1000 Genomes (www.1000genomes.org/), Exome Aggregation Consortium (ExAC) database (http://exac. broadinstitute.org), and the ALS Online Genetics Database (http:// alsod.iop.kcl.ac.uk/) (Abel et al., 2012).

This novel mutation was carried by a female Hungarian patient suffering from sporadic ALS with the latest onset but the fastest progression of the disease (Table 1 ). She had been cured from a breast cancer 8 years before the onset of ALS and proved to be tumor free on following checkups. As first symptoms, the lower extremities became clumsy and weak because of spasticity and muscle atrophy. The calculated ALS Functional Rating Scale R (ALSFRS-R score; Cedarbaum et al., 1999) was 39/48 at the first examination, which was carried out 4 months after the appearance of the first symptoms. Then, the signs of upper and lower motor neuron damage developed fast together with bulbar and pseudobulbar symptoms. She was given $2 \times 50-\mathrm{mg}$ riluzole/day, nevertheless, her status deteriorated quickly, and she became tetraplegic with dysarthria and dysphagia. Respiratory failure developed due to the weakened respiratory muscles, and she died at home.

The SOD1 p.Leu144Phe mutation is located in the fifth exon of the gene and was identified in 2 female ALS patients. One of the patients reported that her maternal grandfather had suffered from nonprogressive paralysis and weakness for 20 years. The other patient reported that her paternal grandmother had suffered from a disease similar to her own. In this study, only the latter patient was therefore considered as having a familial form of the disease. She was the youngest one at the disease onset.

The p.Val14Met mutation is located in the first exon of the SOD1 gene and was present in an affected female patient who reported no family history of ALS. Her first symptoms appeared at the age of 62 . This patient showed lower and upper motor neuron signs. The disease course was progressive and led to the patient's death within 1 year after disease onset.

The p.Asp90Ala mutation, which is the most prevalent SOD1 mutation in Europe (Al-Chalabi et al., 1998; Andersen et al., 2001; Andersen et al., 1995), is located in the fourth exon of the SOD1 gene and was present in a female patient. The patient also carried the rs111273304 splice-donor variant (c.239+2T $>A$ ), which is of 
Table 1

Clinical data of Hungarian ALS patients carrying pathogenic variants in SOD1 and C9orf72 genes

\begin{tabular}{|c|c|c|c|c|c|c|c|}
\hline Gene & $\begin{array}{l}\text { Age of } \\
\text { onset/gender }\end{array}$ & Mutation & Disease signs & $\begin{array}{l}\text { Disease } \\
\text { duration, y }\end{array}$ & Other diseases & $\begin{array}{l}\text { ALS family } \\
\text { history }\end{array}$ & Reference \\
\hline SOD1 & 62/female & p.Val14Met & LMN, UMN & 1 & Lumbar disc protrusions, atherosclerosis & No & Deng et al. (1995) \\
\hline SOD1 & 63/female & p.Asp90Ala & LMN, UMN, B & 12 & Lumbar disc protrusions & No & Andersen et al. (1995) \\
\hline SOD1 & 67/female & p.Lys91ArgfsTer8 & LMN, UMN, B, PB & 1 & $\begin{array}{l}\text { Breast cancer, hypertension, } \\
\text { hypercholesterolemia, spondylosis, and } \\
\text { lumbar disc protrusions }\end{array}$ & No & This study \\
\hline SOD1 & 29/female & p.Leu144Phe & LMN, UMN & 4 & None reported & Yes & Deng et al. (1993) \\
\hline SOD1 & 46/female & p.Leu144Phe & LMN, UMN, B & 3 & Lumbar disc protrusions & No & Deng et al. (1993) \\
\hline C9orf72 & $65 /$ female & Repeat expansion & LMN, UMN & 0.5 & Hyperparathyroidism, multiple lipomas & No & $\begin{array}{l}\text { Dejesus-Hernandez et al. (2011) } \\
\text { and Renton et al. (2011) }\end{array}$ \\
\hline
\end{tabular}

Key: ALS, amyotrophic lateral sclerosis; B, bulbar; LMN, lower motor neuron; PB, pseudobulbar; UMN, upper motor neuron.

unknown significance, in heterozygous form. This patient had clinical features typically associated with this genotype, including a relatively long survival after onset (Andersen, 2006).

Analysis of the C9orf72 gene identified GGGGCC RE in 1 of 66 ALS patients. The average repeat number based on fragment-length analysis was 5 (range: $2-17$ repeats) in the remaining 65 patients, none of whom carried RE. The patient with the RE also carried the rs3849942 risk allele, which was previously described as a part of the Finnish "risk" haplotype (Laaksovirta et al., 2010).
This latter patient (Table 1 ) reported the first symptoms of ALS 6 months before she presented to the neurological unit at age 65 with gradually increasing foot drop on the left side due to peroneal weakness. The ALSFRS-R was 44/48. Three years before admission, an adenoma of one of the parathyroid glands causing hyperparathyroidism was surgically removed, but on admission, the level of the parathyroid hormone in her serum was within normal ranges. A debate whether hyperparathyroidism can mimic ALS has been ongoing for the last 50 years (Jackson et al., 1998).

A

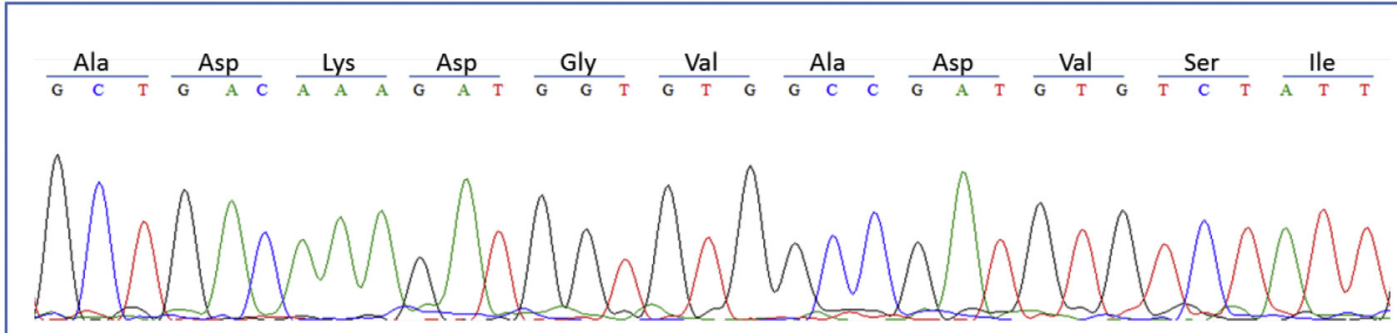

Wild type DNA sequence

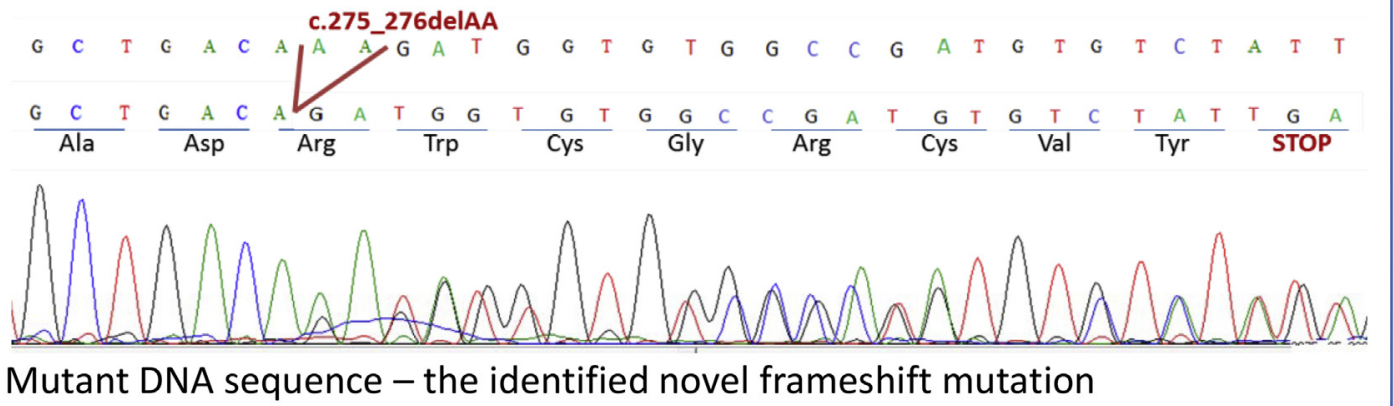

B

Wild type SOD1 protein

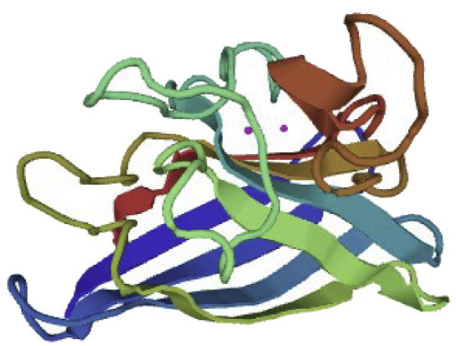

p.Lys91ArgfsTer8 mutant SOD1 protein

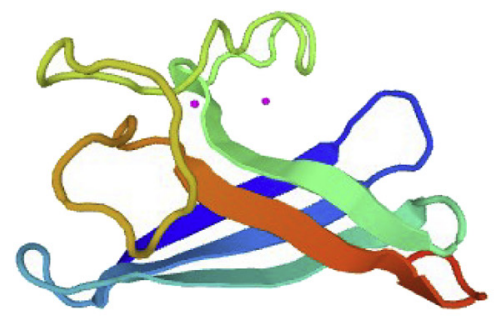

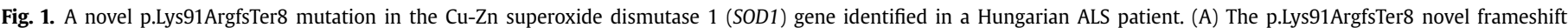

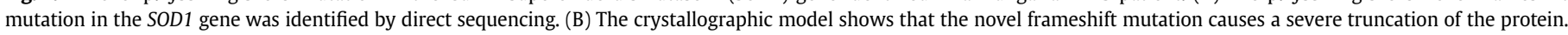
Abbreviation: ALS, amyotrophic lateral sclerosis. 


\section{Discussion}

In this study, we analyzed SOD1 and C9ORF72 genes in a cohort of 66 Hungarian ALS patients, including 1 single case with a reported familial history for the disease. We identified a novel and likely disease-causing heterozygous frameshift mutation (p.Lys91ArgfsTer8) in the SOD1 gene. Three other heterozygous recurrent SOD1 missense mutations (p.Val14Met, p.Asp90Ala, and p.Leu144Phe) were also detected. SOD1 mutations were detected in $7.5 \%(5 / 66)$ of our cohort, in line with literature data reporting that SOD1 mutations account for approximately $0 \%-7 \%$ patients with sporadic disease (Andersen, 2006).

The identified novel p.Lys91ArgfsTer8 SOD1 mutation is associated with a typical ALS phenotype characterized by lower and upper motor neuron signs. The disease had a late onset at the age of 67 years and progressive course leading to the death of the patient within 1 year after the onset of the signs and symptoms of the disease. The 2-base pair deletion of the p.Lys91ArgfsTer8 SOD1 mutation leads to a frameshift with the formation of a premature stop codon after the insertion of 8 novel amino acids, causing a severe truncation of the protein (Fig. 1B). This truncation abolishes the integrity of the intrachain C57-C146 disulfide bridge. Although most mutations in the SOD1 gene are missense ones, a few deletions and insertions have been described previously causing truncations of different sizes and in most cases affecting also the C57-C146 disulfide bridge (http://alsod.iop.kcl.ac.uk/; Abel et al., 2012). The most comprehensively studied truncation mutant is the Gly127insTGGG (G127X), carriers of which developed signs of motor neuron degeneration with a rapid disease course (Jonsson et al., 2004). These observations correlate well with the clinical manifestations and course of ALS in the investigated Hungarian patient with the truncating p.Lys91ArgfsTer8 SOD1 mutation. SOD1 protein with truncating mutations exhibits structural instability causing misfolding in the mutated enzyme (Jonsson et al., 2004), which can consequently aggregate in motor neurons and lead to the development of ALS (Forsberg et al., 2011).

With the exception of the p.Asp90Ala SOD1 mutation, the detected recurrent mutations are all associated with typical ALS phenotypes, characterized by lower and upper motor neuron signs, late onset and progressive disease course. In the case of the patient with the p.Asp90Ala heterozygous mutation, lower limb involvement and relatively long duration of the disease course was detected similarly to cases reported previously (Andersen, 2006; Robberecht et al., 1996). The p.Asp90Ala mutation is the most common SOD1 mutation in Europe (Andersen et al., 2001), and it can be inherited in either a dominant or recessive manner (Robberecht et al., 1996).

The p.Leu144Phe missense mutation, which is the most prevalent mutation in the Balkan region (ALSoD), was detected in a familial and in a sporadic case. The clinical symptoms and the course of the disease were similar in these 2 patients. To note, the patient with a positive family history developed ALS symptoms at a relatively early age, whereas onset for the other patient was late. Although a significant number of patients with this mutation have lower limb onset (Corcia et al., 2011), both of our patients developed upper and lower motor neuron signs. The rare p.Val14Met mutation was detected in an apparently sporadic case in a female patient with upper and lower motor neuron signs. None of the SOD1 mutations detected in these ALS patients was identified in 110 healthy Hungarian controls.

C9orf72 RE was detected only in 1 of 66 patients. The patient carrying the RE variant also carried the previously described rs3849942 risk allele (DeJesus-Hernandez et al., 2011; Laaksovirta et al., 2010) in heterozygous form. According to earlier findings, the "A" allele of SNP rs3849942 was significantly associated to the expanded C9ORF72 allele (DeJesus-Hernandez et al., 2011). We screened 110 controls of Hungarian origin to establish the allele frequencies in this genomic position. The allele frequency of the minor allele in the Hungarian population [MAF $(A)=0.18$ ] correlates well with the data from 1000 Genomes Database (www. 1000 genomes.org/). We observed that the average repeat number was 5 (range: $2-17$ repeats) in the remaining 65 patients who did not carry REs.

In conclusion, we performed the first genetic analysis of SOD1 and C9ORF72 genes in a cohort of Hungarian ALS patients. Our study further widens the geographic range for the origin of diseasecausing heterozygous missense and frameshift mutations of the SOD1 gene, which have already been implicated in ALS patients from different countries of origin. In this study, we identified the hexanucleotide RE of the C9ORF72 gene only in 1 sporadic patient. These results suggest that the frequency of RE observed in the Hungarian ALS patients (1.5\%) is significantly lower than that in Western European populations (Fogh et al., 2014; Majounie et al., 2012; Ratti et al., 2012), further demonstrating that the frequency of genetic factors for ALS varies among different geographic regions.

\section{Disclosure statement}

The authors declare no conflicts of interest.

\section{Acknowledgements}

Funding of the study reported in the article was provided by the Hungarian Brain Research Program (grant no. KTIA_13_NAP-A-II/15, TÁMOP-4.2.2.A-11/1/KONV-2012-0052, and TÁMOP-4.2.2.A-11/1/ KONV-2012-0035).

\section{References}

Abel, O., Powell, J.F., Andersen, P.M., Al-Chalabi, A., 2012. ALSoD: a user-friendly online bioinformatics tool for amyotrophic lateral sclerosis genetics. Hum. Mutat. 33, 1345-1351.

Akimoto, C., Volk, A.E., van Blitterswijk, M., Van den Broeck, M., Leblond, C.S. Lumbroso, S., Camu, W., Neitzel, B., Onodera, O., van Rheenen, W., Pinto, S. Weber, M., Smith, B., Proven, M., Talbot, K., Keagle, P., Chesi, A., Ratti, A., van der Zee, J., Alstermark, H., Birve, A., Calini, D., Nordin, A., Tradowsky, D.C., Just, W., Daoud, H., Angerbauer, S., DeJesus-Hernandez, M., Konno, T., Lloyd-Jani, A., de Carvalho, M., Mouzat, K., Landers, J.E., Veldink, J.H., Silani, V., Gitler, A.D., Shaw, C.E., Rouleau, G.A., van den Berg, L.H., Van Broeckhoven, C. Rademakers, R., Andersen, P.M., Kubisch, C., 2014. A blinded international study on the reliability of genetic testing for GGGGCC-repeat expansions in C9orf72 reveals marked differences in results among 14 laboratories. J. Med. Genet. 51, 419-424.

Al-Chalabi, A., Andersen, P.M., Chioza, B., Shaw, C., Sham, P.C., Robberecht, W. Matthijs, G., Camu, W., Marklund, S.L., Forsgren, L., Rouleau, G., Laing, N.G. Hurse, P.V., Siddique, T., Leigh, P.N., Powell, J.F., 1998. Recessive amyotrophic lateral sclerosis families with the D90A SOD1 mutation share a common founder: evidence for a linked protective factor. Hum. Mol. Genet. 7 2045-2050.

Andersen, P.M., 2006. Amyotrophic lateral sclerosis associated with mutations in the CuZn superoxide dismutase gene. Currneurolneurosci Rep. 6, 37-46.

Andersen, P.M., Nilsson, P., Ala-Hurula, V., Keränen, M.L., Tarvainen, I., Haltia, T. Nilsson, L., Binzer, M., Forsgren, L., Marklund, S.L., 1995. Amyotrophic lateral sclerosis associated with homozygosity for an Asp90Ala mutation in CuZnsuperoxide dismutase. Nat. Genet. 10, 61-66.

Andersen, P.M., Spitsyn, V.A., Makarov, S.V., Nilsson, L., Kravchuk, O.I. Bychkovskaya, L.S., Marklund, S.L., 2001. The geographical and ethnic distribution of the D90A CuZn-SOD mutation in the Russian Federation. Amyotroph. Lateral Scler. Other Mot. Neuron Disord 2, 63-69.

Brooks, B.R., Miller, R.G., Swash, M., Munsat, T.L., 2000. World Federation of Neurology Research group on motor neuron diseases. El Escorial revisited: revised criteria for the diagnosis of amyotrophic lateral sclerosis. Amyotroph. Lateral Scler. Other Mot. Neuron Disord 1, 293-299.

Byrne, S., Elamin, M., Bede, P., Shatunov, A., Walsh, C., Corr, B., Heverin, M., Jordan, N., Kenna, K., Lynch, C., McLaughlin, R.L., Iyer, P.M., O’Brien, C., Phukan, J. Wynne, B., Bokde, A.L., Bradley, D.G., Pender, N., Al-Chalabi, A., Hardiman, O., 2012. Cognitive and clinical characteristics of patients with amyotrophic lateral sclerosis carrying a C9orf72 repeat expansion: a population-based cohort study. Lancet Neurol. 11, 232-240. 
Cedarbaum, J.M., Stambler, N., Malta, E., Fuller, C., Hilt, D., Thurmond, B., Nakanishi, A., 1999. The ALSFRS-R: a revised ALS functional rating scale that incorporates assessments of respiratory function. BDNF ALS Study Group (Phase III). J. Neurol. Sci. 169, 13-21.

Corcia, P., Petiot, P., Stevic, Z., Vourc'h, P., Morales, R., Gordon, P.H., Pageot, N., Andres, C., Camu, W., 2011. Respiratory onset in an ALS family with L144F SOD1 mutation. J. Neurol. Neurosurg. Psychiatry 82, 747.

DeJesus-Hernandez, M., Mackenzie, I.R., Boeve, B.F., Boxer, A.L., Baker, M., Rutherford, N.J., Nicholson, A.M., Finch, N.A., Flynn, H., Adamson, J., Kouri, N., Wojtas, A., Sengdy, P., Hsiung, G.Y., Karydas, A., Seeley, W.W., Josephs, K.A., Coppola, G., Geschwind, D.H., Wszolek, Z.K., Feldman, H., Knopman, D.S., Petersen, R.C., Miller, B.L., Dickson, D.W., Boylan, K.B., Graff-Radford, N.R., Rademakers, R., 2011. Expanded GGGGCC hexanucleotide repeat in noncoding region of C9ORF72 causes chromosome 9p-linked FTD and ALS. Neuron 72, 245-256.

Deng, H.X., Hentati, A., Tainer, J.A., Iqbal, Z., Cayabyab, A., Hung, W.Y., Getzoff, E.D., Hu, P., Herzfeldt, B., Roos, R.P., Warner, C., Deng, G., Soriano, E., Smyth, C., Parge, H.E. Ahmed, A. Roses, A.D. Hallewell, R.A., Pericak-Vance, M.A., Siddique, T., 1993. Amyotrophic lateral sclerosis and structural defects in Cu, $\mathrm{Zn}$ superoxide dismutase. Science 20, 1047-1051.

Deng, H.X., Tainer, J.A., Mitsumoto, H., Ohnishi, A., He, X., Huang, W.Y., Zhao, Y., Juneja, T., Hentatio, A., Siddique, T., 1995. Two novel SOD1 mutations in patients with familial amyotrophic lateral sclerosis. Hum. Mol. Genet. 4, 1113-1116.

Fogh, I., Ratti, A., Gellera, C., Lin, K., Tiloca, C., Moskvina, V., Corrado, L., Soraru, G., Cereda, C., Corti, S., Gentilini, D., Calini, D., Castellotti, B., Mazzini, L., Querin, G., Gagliardi, S., Del Bo, R., Conforti, F.L., Siciliano, G., Inghilleri, M., Sacca, F., Bongioanni, P., Penco, S., Corbo, M., Sorbi, S., Filosto, M., Ferlini, A., Di Blasio, A.M., Signorini, S., Shatunov, A., Jones, A., Shaw, P.J., Morrison, K.E., Farmer, A.E., Van Damme, P., Robberecht, W., Chio, A., Traynor, B.J., Sendtner, M., Melki, J., Meininger, V., Hardiman, O., Andersen, P.M., Leigh, N.P., Glass, J.D., Overste, D., Diekstra, F.P., Veldink, J.H., van Es, M.A., Shaw, C.E., Weale, M.E., Lewis, C.M. Williams, J., Brown, R.H., Landers, J.E., Ticozzi, N., Ceroni, M., Pegoraro, E., Comi, G.P., D'Alfonso, S., van den Berg, L.H., Taroni, F., Al-Chalabi, A., Powell, J., Silani, V. the SLAGEN Consortium and Collaborators, 2014. A genomewide association meta-analysis identifies a novel locus at 17q11.2 associated with sporadic amyotrophic lateral sclerosis. Hum. Mol. Genet. 23, 2220-2231.

Forsberg, K., Andersen, P.M., Marklund, S.L., Brännström, T., 2011. Glial nuclear aggregates of superoxide dismutase- 1 are regularly present in patients with amyotrophic lateral sclerosis. Acta Neuropathol. 121, 623-634.

Gijselinck, I., Van Langenhove, T., van der Zee, J., Sleegers, K., Philtjens, S., Kleinberger, G., Janssens, J., Bettens, K., van Cauwenberghe, C., Pereson, S., Engelborghs, S., Sieben, A., De Jonghe, P., Vandenberghe, R., Santens, P., De Bleecker, J., Maes, G., Bäumer, V., Dillen, L., Joris, G., Couijt, I., Corsmit, E., Elinck, E., Van Dongen, J., Vermeulen, S., Van den Broeck, M., Vaerenberg, C., Mattheijssens, M., Peeters, K., Robberecht, W., Cras, P., Martin, J.J., De Deyn, P.P., Cruts, M., Van Broeckhoven, C., 2012. A C9orf72 promoter repeat expansion in a Flanders-Belgian cohort with disorders of the frontotemporal lobar degeneration-amyotrophic lateral sclerosis spectrum: agene identification study. Lancet Neurol. 11, 54-65.

Hardiman, O., van den Berg, L.H., Kiernan, M.C., 2011. Clinical diagnosis and management of amyotrophic lateral sclerosis. Nat. Rev. Neurol. 7, 639-649.

Hewitt, C., Kirby, J., Highley, J.R., Hartley, J.A., Hibberd, R., Hollinger, H.C., Williams, T.L., Ince, P.G., McDermott, C.J., Shaw, P.J., 2010. Novel FUS/TLS mutations and pathology in familial and sporadic amyotrophic lateral sclerosis. Arch. Neurol. 67, 455-461.

Jackson, C.E., Amato, A.A., Bryan, W.W., Wolfe, G.I., Sakhaee, K., Barohn, R.J., 1998. Primary hyperparathyroidism and ALS, Is there a relation? Neurology 50, 1795-1799.

Jonsson, P.A., Ernhill, K., Andersen, P.M., Bergemalm, D., Brannstrom, T., Gredal, O., Nilsson, P. Marklund, S.L., 2004. Minute quantities of misfolded mutant superoxide dismutase-1 cause amyotrophic lateral sclerosis. Brain 127, 73-88.

Laaksovirta, H., Peuralinna, T., Schymick, J.C., Scholz, S.W., Lai, S.L., Myllykangas, L., Sulkava, R. Jansson, L., Hernandez, D.G., Gibbs, J.R., Nalls, M.A., Heckerman, D., Tienari, P.J., Traynor, B.J., 2010. Chromosome 9p21 in amyotrophic lateral sclerosis in Finland: a genome-wide association study. Lancet Neurol. 9, 978-985.
Majounie, E., Renton, A.E., Mok, K., Dopper, E.G., Waite, A., Rollinson, S., Chio, A. Restagno, G., Nicolaou, N., Simon-Sanchez, J., van Swieten, J.C., Abramzon, Y., Johnson, J.O., Sendtner, M., Pamphlett, R., Orrell, R.W., Mead, S., Sidle, K.C., Houlden, H., Rohrer, J.D., Morrison, K.E., Pall, H., Talbot, K., Ansorge, O., Chromosome 9-ALS/FTD Consortium; French research network on FTLD/FTLD/ALS ITALSGEN Consortium, Hernandez, D.G., Arepalli, S., Sabatelli, M., Mora, G., Corbo, M., Giannini, F., Calvo, A., Englund, E., Borghero, G., Floris, G.L., Remes, A.M., Laaksovirta, H., McCluskey, L., Trojanowski, J.Q., Van Deerlin, V.M., Schellenberg, G.D., Nalls, M.A., Drory, V.E., Lu, C.S., Yeh, T.H., Ishiura, H., Takahashi, Y., Tsuji, S., Le Ber, I., Brice, A., Drepper, C., Williams, N., Kirby, J., Shaw, P., Hardy, J., Tienari, P.J., Heutink, P., Morris, H.R., Pickering-Brown, S. Traynor, B.J., 2012. Frequency of the C9orf72 hexanucleotide repeat expansion in patients with amyotrophic lateral sclerosis and frontotemporal dementia: a cross-sectional study. Lancet Neurol. 11, 323-330.

Morrison, K.E., Harding, A.E., 1994. Disorders of the motor neurone. Baillieres Clin. Neurol. 3, 431-445.

Ratti, A., Corrado, L., Castellotti, B., Del Bo, R., Fogh, I., Ceredag, C., Tiloca, C., D’Ascenzo, C., Bagarotti, A., Pensato, V., Ranieri, M., Gagliardi, S., Calini, D. Mazzini, L., Taroni, F., Corti, S., Ceroni, M., Oggioni, G.D., Lin, K., Powell, J.F. Sorarù, G., Ticozzi, N., Comi, G.P., D’Alfonso, S., Gellerad, C., Silani, V. the SLAGEN Consortium, 2012. C9ORF72 repeat expansion in a large Italian ALS cohort: evidence of a founder effect. Neurobiol. Aging 33, 2528.e7-2528.e14.

Renton, A.E., Majounie, E., Waite, A., Simon-Sanchez, J., Rollinson, S., Gibbs, J.R. Schymick, J.C., Laaksovirta, H., van Swieten, J.C., Myllykangas, L., Kalimo, H. Paetau, A., Abramzon, Y., Remes, A.M., Kaganovich, A., Scholz, S.W. Duckworth, J., Ding, J., Harmer, D.W., Hernandez, D.G., Johnson, J.O., Mok, K. Ryten, M., Trabzuni, D., Guerreiro, R.J., Orrell, R.W., Neal, J., Murray, A., Pearson, J., Jansen, I.E., Sondervan, D., Seelaar, H., Blake, D., Young, K., Halliwell, N., Callister, J.B., Toulson, G., Richardson, A., Gerhard, A., Snowden, J., Mann, D., Neary, D., Nalls, M.A., Peuralinna, T., Jansson, L., Isoviita, V.M., Kaivorinne, A.L., Holtta-Vuori, M., Ikonen, E., Sulkava, R., Benatar, M., Wuu, J., Chio, A., Restagno, G., Borghero, G., Sabatelli, M., Heckerman, D., Rogaeva, E., Zinman, L., Rothstein, J.D., Sendtner, M., Drepper, C., Eichler, E.E., Alkan, C. Abdullaev, Z., Pack, S.D., Dutra, A., Pak, E., Hardy, J., Singleton, A., Williams, N.M., Heutink, P., Pickering-Brown, S., Morris, H.R., Tienari, P.J., Traynor, B.J., 2011 A hexanucleotide repeat expansion in C9ORF72 is the cause of chromosome9p21-linked ALS-FTD. Neuron 72, 257-268.

Robberecht, W., Aguirre, T., Van den Bosch, L., Tilkin, P., Cassiman, J.J., Matthijs, G., 1996. D90A heterozygosity in the SOD1 gene is associated with familial and apparently sporadic amyotrophic lateral sclerosis. Neurology 47, 1336-1339.

Rosen, D.R., Siddique, T., Patterson, D., Figlewicz, D.A., Sapp, P., Hentati, A., Donaldson, D., Goto, J., O'Regan, J.P., Deng, H.X., Rahmani, Z., Krizus, A. McKenna-Yasek, D., Cayabyab, A., Gaston, S.M., Berger, R., Tanzi, R.E., Halperin, J.J., Herzfeld, B., Bergh, R.V.D., Hung, W.Y., Bird, T., Deng, G., Mulder, D.W., Smyth, C., Laing, N.G., Soriano, E., Pericake Vance, M.A., Haines, J., Rouleau, G.A., Gusella, J.S., Horvitz, H.R., Brown, J.R., Robert, H., 1993. Mutationsin $\mathrm{Cu} / \mathrm{Zn}$ superoxide dismutase gene are associated with familial amyotrophiclateral sclerosis. Nature 362, 59-62.

Smirnoff, N., 1993. The role of active oxygen in the response of plants to water deficit and desiccation. New Phytol. 125, 27-58.

Smith, B.N., Newhouse, S., Shatunov, A., Vance, C., Topp, S., Johnson, L., Miller, J., Lee, Y., Troakes, C., Scott, K.M., Jones, A., Gray, I., Wright, J., Hortobágyi, T., AlSarraj, S., Rogeli, B., Powell, J., Lupton, M., Lovestone, S., Sapp, P.C., Weber, M. Nestor, P.J., Schelhaas, H.J., Asbroek, A.A., Silani, V., Gellera, C., Taroni, F., Ticonni, N., Van Den Berg, L., Veldink, J., Van Damme, P., Robberecht, W., Shaw, P.J., Kirby, J., Pall, H., Morrison, K.E., Morris, A., de Belleroche, J., Vianney de Jong, J.M. Baas, F., Andersen, P.M., Landers, J., Brown Jr., R.H., Weale, M.E., Al-Chalabi, A. Shaw, C.E., 2013. The C9ORF72 expansion mutation is a common cause of ALS +/FTD in Europe and has a single founder. Eur. J. Hum. Genet. 21, 102-108.

Strong, M.J., Hudson, A.J., Alvord, W.G., 1991. Familial amyotrophic lateral sclerosis 1850-1989: a statistical analysis of the world literature. Can J. Neurolsci 18 45-58.

Taylor, J.P., Brown Jr., R.H., Cleveland, D.W., 2016. Decoding ALS: from genes to mechanism. Nature 539, 197-206. 